\title{
El final del relato. Arte, historia y narración en la filosofía de Arthur C. Danto
}

\author{
VERÓNICA PARSELIS \\ Pontificia Universidad Católica Argentina \\ Escuela de Ciencias Políticas \\ verute@parselis.com.ar
}

\begin{abstract}
Resumen: El artículo muestra el giro hacia la consideración histórica que permite al filósofo Arthur C. Danto acceder a una comprensión del arte contemporáneo. Se desarrolla en primer lugar la temprana contribución de Danto en el terreno de la filosofía de la historia, para luego confrontarla con su posterior filosofía de la historia del arte, abriendo la discusión acerca de la afirmación de Hegel de que la historia del arte ha finalizado. La historia del arte ha llegado a su fin, proclama Danto, y nosotros ahora vivimos en una era posthistórica. Estas consideraciones parecen haber abierto un camino nuevo para la interpretación del arte del presente.
\end{abstract}

Palabras clave: fin del arte, narrativas, G.W.F. Hegel, arte contemporáneo

\begin{abstract}
The article focus on the way in wich Arthur C. Danto transformed his first consideration of art into a historical account. The history of art has ended, Danto claims, and we live in a posthistorical era. Since in his first book on historiography Danto is unsympathetic to Hegel's philosophy, his new adaptation of the Hegelian framework is unexpected. In this process, he opened up a discussion of the original Hegel's claim that the history of art has ended. These considerations seem to open a new road for the interpretation of the art of today.
\end{abstract}

Key words: end of art, narratives, G.W.F. Hegel, contemporary art

\section{Introducción}

Al analizar el arte contemporáneo como un lúcido testigo de nuestro tiempo, el filósofo Arthur C. Danto le ha atribuido una misión: descubrir la esencia del arte. Danto cree que ésta fue la preocupación central de la vanguardia desde su origen, y es una misión filosófica que se ha cumplido implícitamente en los años sesenta. ${ }^{1}$ Alcanzar la esencia del arte ha servido para completar la historia del arte, introduciendo de este modo la era posmoderna del arte o, en sus propios términos, la era posthistórica. $^{2}$

${ }^{1}$ Fundamentalmente por la obra de Andy Warhol, artista norteamericano clave del arte pop, en quien Danto ve el ápice de las vanguardias, como veremos en el desarrollo posterior de este trabajo.

${ }^{2}$ Danto establece una clara delimitación entre las nociones de "arte moderno", "arte contemporáneo" y "arte posmoderno". "Moderno" no es un concepto tempo- 
Mientras los primeros escritos de Danto se preocupaban por hallar las condiciones para una definición de la obra de arte y así poder dotarla de un contexto en el cual su interpretación, en cuanto obra, fuese posible, su interés poco a poco se desplaza hacia la necesidad de comprender el carácter histórico del arte. Existen determinadas condiciones que trascienden el aquí y el ahora para que un objeto sea considerado arte, pero al mismo tiempo encontramos determinadas condiciones históricas que hacen posible que un objeto cualquiera -la Brillo Box de Warhol, por ejemplo- sea considerado arte en el siglo XX, pero no antes.

El giro de Danto hacia la filosofía de la historia del arte se produce definitivamente en su obra After the End of Art. En este texto transformó el análisis puramente filosófico de su obra estética ${ }^{3}$ anterior en una consideración histórica. Su análisis ahora proporciona una manera de explicar el desarrollo del arte en el período moderno. Danto cambia radicalmente el contexto de su argumento. En este proceso abre la discusión sobre su tesis original y sobre la plausibilidad de la afirmación de Hegel de que la historia del arte ha finalizado. La historia del arte ha llegado a su fin, proclama Danto, y nosotros ahora vivimos en una era posthistórica.

Desarrollaremos en primer lugar la contribución de Danto en el terreno de la filosofía de la historia, para luego enfrentarla a su posterior filosofía de la historia del arte, que ha abierto un camino nuevo para la interpretación del destino del arte y su posibilidad histórica.

\section{Filosofía de la historia: el narrativismo de Danto}

Su conocido libro sobre historiografía, Analytical Philosophy of History, es un texto que en su conjunto se presenta como el resultado de una reflexión anterior que puede leerse en los artículos "On Historical Questioning" y "Mere Chronicle and History Proper". En esta obra confluyen

ral, sino que refiere al arte de las vanguardias propiamente dicho, que significó una reacción contra el arte "del pasado". El "arte contemporáneo", por su parte, no reacciona contra el arte del pasado sino que él mismo "está disponible para el uso de los artistas" convirtiendo al collage en uno de sus paradigmas. El término "posmoderno" identifica, en cambio, un sector del arte contemporáneo, cierto estilo con características específicas, un subgrupo dentro de la producción posterior al modernismo con elementos diferenciadores. La noción de arte "posthistórico" es la que propone Danto para el arte contemporáneo, período de libertad y pluralismo donde no hay linde de la historia. Cfr. A.C. Danto, Después del fin del arte, cap. 1.

${ }^{3}$ Cfr. A.C. Danto, The Transfiguration of the Commonplace, versión en castellano: La transfiguración del lugar común: una filosofía del arte. 
tanto la problemática afrontada por la filosofía neopositivista de la historia, como el inicio del cambio de orientación que, a partir de los años sesenta, tiene lugar en el ámbito de la filosofía de la historia anglosajona.

Danto mismo ha dicho sobre este texto que se "trata de un libro [...] que debe su existencia al artículo de Hempel". Dicho artículo, titulado "La función de las leyes generales en la historia", ${ }_{4}$ apareció en 1942 como un intento neopositivista de reconducir la historiografía al denominador común de las ciencias empíricas. En cambio, el libro de Danto va a introducir nociones que se apartan claramente de estos límites. ${ }^{5}$ Danto parecería contraponerse a Hempel al situarse en una visión sobre la historia totalmente distinta: sus palabras indicarían el origen de un campo de reflexiones que presta especial atención al papel de la narración en la historia y el marco desde el que fueron elaboradas las interpretaciones. ${ }^{6}$

Hagamos una mención al modelo de Hempel para entender, en contraposición, la propuesta de Danto. Hempel trata de mostrar la presencia - aunque sólo sea en esbozo- del modelo nomológico-deductivo de explicación en la historia, y con ello se aleja tanto de la distinción entre ciencias naturales y ciencias del espíritu (tematizada por Dilthey), cuanto de la vigencia de cualquier tipo de filosofía especulativa de la historia. La historia ha sido, en manos de "filósofos especulativos de la historia" como Kant, Herder o Hegel, fuente de innumerables teorías metafísicas que consideraban la historiografía una referencia obligada con el fin de mostrar la insuficiencia de los conceptos empiristas de experiencia y de racionalidad para dar cuenta de lo humano.

Hempel pone el acento en el problema de la explicación. Su modelo, que fue establecido desde un marcado interés por la ciencia natural y un fuerte talante antimetafísico, se concibe como aplicable a cualquier discurso que pretenda tener valor cognoscitivo. Desde la aparición del mencionado artículo de Hempel hasta casi el final de los años sesenta y el inicio de los setenta, la controversia principal de los filósofos de la ciencia con respecto al conocimiento histórico se desarrolla en torno al problema de si el modelo de explicación nomológico-deductivo, propio de las ciencias naturales, es o no válido para la historiografía; es decir,

${ }^{4}$ C. Hempel, "The Function of General Laws in History"; una versión en castellano se incluye en La explicación científica.

${ }^{5}$ Jürgen Habermas llega a afirmar incluso que Danto "conduce la filosofía analítica al umbral mismo de la hermenéutica" (J. Habermas, La lógica de las ciencias sociales, p. 115).

${ }^{6}$ Cfr. F. Birulés, “Introducción”, en A.C. Danto, Historia y narración. 
si los historiadores explican según este modelo, o si este modelo puede asumirse como base del conocimiento producido por esa disciplina. ${ }^{7}$

El supuesto esencial es la tesis de la unidad del modelo de explicación científica, que aparece como el único camino abierto para asegurarle a la investigación histórica el derecho a la ciudadanía en el dominio de la ciencia. Desde esta perspectiva, la argumentación estará dirigida básicamente en contra de la comprensión como método específico de la historiografía para producir conocimiento y, por tanto, el rechazo de cualquier tipo de distinción entre las ciencias naturales y las ciencias sociales.

El propio Hempel advierte la limitada aplicabilidad de este modelo a la historiografía al sostener que esta disciplina, en cuanto que no es una ciencia desarrollada, no ofrece explicaciones completas, sino tan sólo "esbozos de explicación". La diferencia entre las explicaciones científicas ideales y los esbozos de la historiografía radica en la falta de precisión de los segundos, no en su forma lógica.

El modelo nomológico-deductivo de explicación es conocido también como Covering Law Model [modelo de cobertura legal], ${ }^{8}$ subrayando así que, en este contexto, ofrecer una explicación es subsumir lo que queremos explicar bajo una ley general. De este modo, un acontecimiento queda explicado cuando es "cubierto" por una ley y sus antecedentes (que son legítimamente sus causas).

Así, pues, como las leyes desempeñan una función análoga en la historia y en la ciencia natural, las explicaciones históricas no pueden aspirar a ningún estatus epistemológico particular, con lo que queda descartada cualquier caracterización que haga de la ciencia de la historia un discurso privilegiado o sui generis por el mero hecho de que su objeto sea lo humano, como han pretendido los filósofos idealistas e historicistas; todo discurso que aspire a merecer el calificativo de "cognoscitivo" debe tener —al menos implícitamente— la misma estructura lógica.

Las limitaciones del Covering Law Model (CLM) empiezan a manifestarse tan pronto como, desde el marco de la misma filosofía analítica, se intenta medir la aplicabilidad del modelo al trabajo de los historiadores. Las dificultades surgen en el momento en que un modelo tan acentuadamente normativo se confronta con el conocimiento histórico de facto.

${ }^{7}$ Cfr. C. Yturbe, "El conocimiento histórico", pp. 207-228.

${ }^{8}$ La denominación se debe a W. Dray. Cfr. Laws and Explanation in History. 
El debilitamiento del modelo se da fundamentalmente a raíz de la introducción de temas y argumentos que habían sido característicos de posturas idealistas o historicistas en la controversia acerca del CLM. Por ejemplo, el argumento de la unicidad y la inclasificabilidad de los acontecimientos históricos, o el énfasis en el hecho de que cuando el historiador ofrece explicaciones, no se limita a apelar a leyes, sino que a menudo hace referencia a intenciones, planes o propósitos. Así, se empieza a aceptar que hay explicaciones de la conducta que no son causales en el sentido señalado por el modelo.

A partir del diálogo con la obra de R.G. Collingwood, por ejemplo, se vuelve a conceder - en el marco de la filosofía analítica de la historiacierto crédito a la perspectiva historicista. ${ }^{9}$ La discusión con Hempel alcanzó su punto crítico entonces, cuando ya resultaba difícil avanzar sin romper con la hipótesis central según la cual la explicación histórica no difiere en lo fundamental de la explicación en el resto de las ciencias; es decir, mediante la subsunción del acontecimiento por explicar bajo una ley general. La única vía que parecía abrirse para captar la especificidad del conocimiento histórico era justamente la consideración del problema desde el punto de vista opuesto: el reconocimiento del carácter narrativo de la historia y, por tanto, la recuperación de la comprensión como momento fundamental de dicho conocimiento. ${ }^{10}$

Con la publicación de Analytical Philosophy of History de Danto, en 1965 se introduce en la filosofía anglosajona de la historia la noción de narración. ${ }^{11}$ De todos modos, todavía se insiste en el carácter explicativo de la estructura narrativa como alternativa a la explicación causal, derivada de la concepción científica.

La obra de Danto se enmarca, pues, en el proceso de debilitamiento o abandono del mencionado modelo nomológico-deductivo de explicación. Y, como ha indicado Habermas, el libro de Danto va más allá de este modelo. "Donde no hay narrador no hay historia". ${ }^{12}$ Analytical Philosophy of History se organiza alrededor de la idea de que la reconstrucción del sentido de los acontecimientos históricos no se reduce a la recuperación del contexto y de la perspectiva de los agentes y testimo-

${ }^{9}$ Cfr. R.G. Collingwood, Idea de la historia. Esta reconsideración de los argumentos historicistas no es extraña, en algunos casos, a la influencia del pensamiento del segundo Wittgenstein. Cfr. P. Winch, The Idea of Social Science.

${ }^{10}$ Cfr. C. Yturbe, op. cit., pp. 207-228.

${ }^{11}$ Esta atención al papel de la narración puede apreciarse también en obras contemporáneas a Danto como: Historical Knowledge de Morton White y Philosophy and Historical Understanding de William Gallie. Cfr. F. Birulés, loc. cit.

${ }^{12}$ A.C. Danto, Historia y narración, p. 22. Cfr. nota 5 de este trabajo. 
nios inmediatos. Entonces, el significado se halla ligado a la consciencia retrospectiva de intérpretes históricamente situados.

Por lo tanto, en el interior mismo de la filosofía analítica, en el contexto del "giro lingüístico", esto es, del cambio de posición frente al problema del lenguaje, la filosofía de la historia irá abandonando el tema de la explicación como problema central, para abocarse al análisis de los diferentes usos y fines del lenguaje en la práctica historiográfica. Del problema de la causalidad (= explicación) se pasará al problema de la interpretación del pasado en términos de exégesis y entendida como la comprensión de la lógica propia de las acciones humanas (= comprensión).

La obra de Danto fue decisiva para la defensa, en el interior de la filosofía analítica, de la concepción según la cual el conocimiento de la historia se produce a través de una narración, no de una explicación. Esta narración es autoexplicativa, es decir, capaz de explicar los acontecimientos narrados sin necesidad de referirse a elementos externos a la narración misma. La estructura intrínseca de la narración se convierte en la categoría sobre la que se basa la especificidad de la disciplina historiográfica.

El rasgo distintivo de la narración es la trama, el argumento, la urdimbre de sentido. Narrar no es describir una serie de acontecimientos, sino producir sentido por medio de la reconstrucción de una trama. A partir de la invención de una intriga, "síntesis de lo heterogéneo", dira Ricœur, los fines, los medios, las causas, las circunstancias, los azares, se ven reunidos bajo la unidad temporal de una acción total y completa. Uno de los atractivos de esta posición es que parece respetar lo que realmente hacen los historiadores, y no imponerles una concepción de cientificidad ajena. ${ }^{13}$

La narrativa, al tener la forma de un relato que se cuenta, subraya su preocupación por los sujetos y las razones de sus acciones (haciendo a un lado la idea de que fuerzas impersonales actúan detrás de ellos). Así, se vuelve necesario un tratamiento más adecuado de las secuencias temporales en la historia, con una inclinación a rechazar las generalizaciones "atemporales".

La narrativa permite la presencia de un estilo literario de una manera que resultaba impensable con el uso de proposiciones extraídas de la sociología o de la física. De ahí la existencia de cierta tendencia a reducir la historiografía a un género literario. ${ }^{14}$ En tanto la historia se

${ }^{13}$ C. Yturbe, op. cit., p. 213. Cfr. P. Ricœur, Tiempo y narración.

${ }^{14} \mathrm{H}$. White, Metahistory: The Historical Imagination in Nineteenth-Century Europe.

Diánoia, vol. LIV, no. 62 (mayo 2009). 
conciba como una narración explícita o implícita, el lenguaje ocupará el centro de los análisis históricos. ${ }^{15}$

Danto reafirma la tesis del carácter autoexplicativo de la narración histórica centrando su análisis en la "oración narrativa". Ésta se refiere a por lo menos dos acontecimientos temporalmente distintos, vinculados por una relación de sucesión. Las "oraciones narrativas" describen no un estado de cosas, sino un cambio, poniendo a la luz las consecuencias de ciertos acontecimientos y estableciendo así nexos causales entre acontecimientos, para lo cual el historiador utilizará enunciados de carácter general.

Una "filosofía analítica de la historia" consistirá en tomar en serio la limitación característica del conocimiento histórico (esto es, nuestra ignorancia del futuro) y analizar las formas de hablar del pasado, que son, al mismo tiempo, formas de concebirlo. Este tipo de filosofía de la historia se contrapone a las denominadas "filosofías sustantivas de la historia" que tratan de dar cuenta del significado del "conjunto de la historia": conjunto que incluye tanto el pasado como el futuro, pues la "filosofía sustantiva de la historia" tiene como finalidad buscar el sentido general del destino del hombre sobre la tierra, ya sea que dicha búsqueda se lleve a cabo considerando el proceso histórico globalmente, ya sea que, bajo la influencia de las ciencias sociales, esa búsqueda tenga que ver con la investigación de las leyes y constantes de toda civilización. El desarrollo de este tipo de filosofía de la historia está estrechamente ligado a una idea de progreso, en virtud de lo cual a medida que la idea misma de progreso entraba en crisis, la filosofía sustantiva de la historia se adentraba en la vía de su agotamiento. ${ }^{16}$

El historiador, en cambio, tiene como objetivo en primer lugar hacer afirmaciones verdaderas sobre el pasado y sobre el futuro, pero cuando éste ha devenido pasado; $y$, en segundo lugar, hacer un uso del concepto de significado considerablemente distinto. El historiador, entonces, considera el significado de los acontecimientos pasados en relación con una totalidad temporal. Sólo retrospectivamente nos sentimos autorizados a atribuir un significado a tal o cual acontecimiento. Por tanto, la pregunta por el significado sólo puede tener respuesta en un relato. ${ }^{17}$

La "filosofía sustantiva de la historia" peca de impaciencia, trata de ofrecer un relato antes de que pueda ser propiamente contado. Pero un relato completo del pasado implicaría un relato completo del futuro y,

${ }^{15}$ Cfr. C. Yturbe, loc. cit.

${ }^{16}$ Ibid., p. 225.

${ }^{17}$ Danto, A.C., Historia y narración, p. 24. 
por otra parte, todo discurso narrativo es esencialmente incompleto. El historiador habla desde un horizonte temporal que no es el del testimonio ocular, pero ésta es la condición de posibilidad de todo significado o conocimiento histórico.

La "oración narrativa", presentada por Danto como una de las descripciones posibles de la acción, recoge estas consideraciones. Siempre narramos una historia (story) desde la perspectiva de su conclusión. Por tanto, los dos acontecimientos a que se refiere una "oración narrativa" son siempre anteriores al momento de su enunciación. Entonces, hay que entender que la historiografía va más allá de lo dado y maneja esquemas organizativos: la narración histórica organiza y al mismo tiempo interpreta. Para Danto, la "historia es de una sola pieza". Toda descripción interpreta. Sin criterios de selección no hay historia, porque los acontecimientos históricos sólo adquieren significado histórico gracias a su relación con acontecimientos posteriores, a los que el historiador concede importancia en función de sus intereses presentes.

Por tanto, no hay historia (en el sentido narrativo del término) del presente: porque el futuro está abierto. No sabemos cómo organizarán nuestro presente los futuros historiadores o incluso nosotros mismos. Pero si el futuro está abierto, podemos decir que el pasado también lo está en algún sentido. La imposibilidad de situarnos "literalmente" en el lugar de otro es, al mismo tiempo, la limitación del conocimiento histórico y la condición de posibilidad de una narración significativa del pasado. La historia no puede concebirse como imitación de la historia vivida. La narración histórica no es, por tanto, un mero vehículo de transmisión de información. La narración es un procedimiento de producción de significado. Y por ser un procedimiento de producción de significado, puede atribuírsele una función explicativa.

En la obra de Danto se atribuye una función explicativa a la narración, pero no hay que olvidar que la historia sólo la podemos conocer desde dentro; es decir, como sujetos históricamente situados en un momento posterior a los hechos relatados. Las historias que contamos dicen tanto de nuestro pasado como de nuestros intereses presentes. En cierto sentido, somos un microcosmos de las historias que somos capaces de narrar. Esto es lo que a Habermas le permite afirmar que Danto lleva a la filosofía analítica al umbral mismo de la hermenéutica. El historiador no habla desde afuera. La historia no es una reflexión impersonal, sino que es una disciplina subjetiva, en el doble sentido de ser el marco en cuyo seno podemos autorrepresentarnos y, al mismo tiempo, marco en el cual el historiador no es espectador, sino partícipe. 
La corriente narrativista produjo un cambio cualitativo en la manera tradicional de abordar la historia. Los historiadores, pues, reconocen el papel activo que desempeñan el lenguaje, los textos y las estructuras narrativas en la creación y descripción de la realidad histórica.

Todo lo visto hasta aquí es fundamental para comprender la nueva aportación a la filosofía del arte en su obra posterior, After the End of Art. Allí introduce su filosofía de la historia del arte a partir del análisis de las narrativas del arte occidental. Este libro parece enlazar las problemáticas de la definición del arte y su posibilidad en la historia. Intentaremos ahora elucidar algunas de las nuevas cuestiones que Danto considera para hacer posible dicho enlace.

\section{Filosofía de la historia del arte}

Si pensamos en la "historia del arte" como una rama especial de la historia, esa división de la historia que se interesa por un tipo particular de objetos, entonces es sorprendente que los historiadores del arte interesados en la metodología no presten una seria atención a la historiografía.

El interés de Danto por la historiografía y su interés por la estética parecen ocuparse en principio de cuestiones diversas; los argumentos de su libro Transfiguration of the Commonplace no necesitarían el respaldo de las afirmaciones de su Analytical Philosophy of History. El primero está preocupado centralmente por definir el arte y mostrar las consecuencias de la definición para la práctica de la interpretación, discutiendo contra los relatos tradicionales que definen el arte como representación o como una forma de expresión. Analytical Philosophy of History, por su parte, discute contra la afirmación de Carl G. Hempel y muestra que se alcanza una mayor comprensión de la historia al identificar el rol de las narrativas. En estos dos libros Danto considera temas muy distintos, aunque comparten un mismo estilo.

En su obra After the End of Art, texto fundamental para continuar con este análisis, Danto realiza un giro sorprendente al proponer una filosofia de la historia del arte. La noción de narrativa es ahora aplicada a la historia del arte mismo. La historia — del arte — se organiza y se interpreta en unidades narrativas, que permiten la producción de significado, una urdimbre de sentido que brota de un intérprete históricamente situado. Se narra la historia del arte desde la perspectiva de su conclusión. Ahora se vuelven centrales algunas observaciones que cuando las presentó en 1981 en The Transfiguration... parecían de significación marginal: 
No todo es posible en cualquier momento [...], ciertas obras de arte simplemente no pueden ser insertadas como obras de arte en ciertos períodos de la historia del arte, aunque sea posible que objetos idénticos a obras de arte puedan ser hechos en ese periodo. ${ }^{18}$

La frase "no todo es posible en todo momento" alude a la consideración historicista de Heinrich Wölfflin, ${ }^{19}$ cuyo punto de vista es recogido en Después del fin del arte:

En todo caso, dado el estado del arte en 1790, una bujía no hubiera podido ser una obra de arte. Hoy en día sí podría serlo, como consecuencia de la revolución engendrada por alguna de las travesuras de Marcel Duchamp alrededor de $1917 \mathrm{y}$, con todo, no a causa de su belleza. ${ }^{20}$

Si la pregunta en sus obras anteriores era qué hacía que la Brillo Box de Warhol sea una obra de arte a diferencia de su indiscernible ${ }^{21}$ del

${ }^{18}$ A.C. Danto, La transfiguración del lugar común, p. 44.

${ }^{19}$ Cfr. A.C. Danto. "Art, Essence, History and Beauty", p. 285. Cfr. H. Wölfflin, Principles of Art History; versión en castellano: Conceptos fundamentales de la historia del arte.

${ }^{20}$ A.C. Danto, Después del fin del arte, p. 100. Es curioso que la narrativa de Danto termine con Warhol y no con Duchamp. Esto ha sido fuente de innumerables críticas. Pero hay un lazo ineludible entre el arte de Duchamp y el arte pop posterior, principalmente en cuanto a la recuperación de determinadas consignas y elementos de la expresión plástica. Debe buscarse este lazo en el histórico traspaso de las vanguardias europeas a Estados Unidos. El desarrollo de esa búsqueda se continúa, sin duda, en Nueva York. Nadie más ha interpretado la realización de Warhol del modo en que lo ha hecho Danto: por un lado, una tradición marxista elogió a Warhol por criticar la commodification de la cultura burguesa; por otra parte, algunos admiradores del expresionismo abstracto y mucha gente interesada en el arte "estéticamente agradable" lo odiaron. Es evidente que una razón para que Warhol se haya vuelto uno de los artistas más influyentes en la última mitad del siglo $\mathrm{xx}$ es que son posibles muchas perspectivas y reflexiones diversas sobre su obra.

${ }^{21}$ El método de los indiscernibles nos permite, según Danto, arribar a la definición del arte dirigiendo la mirada más allá de las propiedades sensibles del objeto. El arte contemporáneo nos ha puesto ante la incógnita de la identificación del arte, ante dos objetos perceptualmente idénticos, ¿por qué uno es arte y el otro no? Ése es el problema filosófico fundamental al que Danto intenta responder afirmando que las condiciones necesarias y suficientes para que un objeto sea una obra de arte son: que sea "sobre algo" (aboutness) y que "encarne" ese significado adecuadamente (embodiment). Esto conlleva, por su carácter semántico, que toda obra es materia de interpretación. Hay una conexión interna entre toda obra de arte y su entorno teórico e interpretativo. La necesidad de la interpretación es inherente al concepto de arte. Cfr. A.C. Danto, La transfiguración del lugar común. 
mundo cotidiano, Danto se pregunta ahora qué la hace posible en 1964, cuando es claro que un objeto como Brillo Box no podría haber sido una obra de arte en ningún momento anterior. Dice a este respecto:

Esto es lo que yo denominé el problema de las modalidades históricas (las modalidades lógicas canónicas son la posibilidad, la imposibilidad y la necesidad), y una fuerte filosofía de la historia debería preguntar: ¿qué hace a las Brillo Box históricamente necesarias en 1964? Heinrich Wölfflin tuvo justamente un sentido vívido de las modalidades históricas entendidas en términos de imperativos históricos cuando escribió [...] que "no todo es posible en todos los tiempos". [...] Inevitablemente tengo que convenir con Wölfflin, y lo hago alejando la atención desde los estilos hacia la dirección de un análisis que es dependiente de la cuestión ontológica. ${ }^{22}$

Según Danto, pues, la historia del arte moderno debe ser contada precisamente en esos términos: como una búsqueda filosófica. Danto, entonces, sugiere que las obras de arte están ontológicamente arraigadas en la modalidad histórica; esto es, parafraseando a Wölfflin, que no todo lo que es una obra de arte en un momento histórico determinado lo es en todo momento. ${ }^{23}$ Por lo tanto, la esencia del arte es llevada a la conciencia a través de la historia. Se pone de manifiesto el modo en que las preocupaciones historiográficas penetraron sus escritos sobre teoría estética.

Danto expresa que "el concepto de arte, como esencialista, es eterno". Lo que agrega ahora es la noción de que la extensión del término debe ser considerada históricamente, dado que es como si "verdaderamente [...] la esencia se revelara a sí misma a través de la historia". Por lo tanto, la historia pertenece a la extensión, más que a la intensión del concepto de arte. Danto asocia este pensamiento al expresado

${ }^{22}$ A.C. Danto, "Works in Progress: Art and the Historical Modalities". H. Wölfflin (1864-1945), junto con A. Riegl (1858-1905), es considerado uno de los máximos exponentes del formalismo en estética. El interés de Wölfflin estaba en la posibilidad estilística y en lo que pensó como las "leyes del cambio estilístico". Adoptando la teoría de la visibilidad pura en sus Kuntsgeschichtliche Grundbegriffe (Conceptos fundamentales de la historia del arte), trata lo lineal y lo pictórico como dos grandes tipos generales y opuestos de visión o "categorías de intuición". Son dos polos entre los cuales oscila periódicamente el arte entero. Al intentar poner en evidencia el sustrato óptico que, no obstante sus variaciones, se encuentra en la base de las representaciones estéticas más diferentes en el curso de los siglos, Wölfflin piensa que es posible seguir el desarrollo de la visión, que tiene una necesidad interna y en el que las diferencias individuales y nacionales no tienen la menor influencia.

${ }^{23}$ A.C. Danto, "Works in Progress: Art and the Historical Modalities". 
por Wölfflin en sus escritos sobre los cambios artísticos y el desarrollo histórico. El supuesto fundamental es que la historia del arte obedece a una lógica interna, a leyes de desarrollo propias e inmanentes, independientes de los influjos externos tales como las condiciones de vida sociales y la psicología individual de los artistas. Danto coincide con Wölfflin precisamente en explicar el desarrollo de la historia a partir de una necesidad interna. ${ }^{24}$

Tomando como base su concepción narrativista de la historia, que considera la narrativa como un procedimiento de carácter autoexplicativo, Danto propone una nueva mirada sobre el arte. Recordemos que la narrativa, al tener la forma de un relato que se cuenta, vuelve necesario un tratamiento más adecuado de las secuencias temporales en la historia. Danto ofrece ahora una reflexión sobre las narrativas maestras que han gobernado el arte occidental desde el comienzo del Renacimiento hasta el advenimiento del arte pop.

Danto divide la historia del arte occidental en cuatro etapas. La primera es el período prehistórico, o lo que él denomina, basándose en la obra de Hans Belting, "el arte antes del comienzo del arte". ${ }^{25} \mathrm{El}$ arte propiamente dicho, se dice, empieza alrededor del 1300 con la inauguración de la "primera gran narrativa del arte". Ésta es la narrativa de la gradual conquista de la apariencia visual, el intento de replicar por medio de la pintura los efectos que las superficies del mundo imprimen sobre el ojo humano. Esta narrativa era suficientemente poderosa para generar un desarrollo histórico progresivo del arte que duró cerca de seiscientos años, pero que llegó a su fin a fines del siglo XIX. La obra

${ }^{24}$ Podemos mencionar nuevamente a Alois Riegl, que ofrece una explicación de la historia del arte ligada al desarrollo de una necesidad inmanente, oponiéndose a la idea de un proceso mecánico provocado por las condiciones externas. Riegl aproximó la concepción histórica a la de visibilidad, reemplazando el concepto de determinismo artístico por el de "voluntad de arte" (Kunstwollen), una suerte de intencionalidad artística supraindividual que suscita los distintos cambios estilísticos.

${ }^{25}$ H. Belting, Likeness and Presence: A History of Image before the Era of Art. Quisiera aclarar aquí cómo se entiende el arte anterior al Renacimiento, dado que puede ser confusa esta clasificación. No se sostiene que las "imágenes piadosas del Occidente cristiano" no sean arte en un sentido amplio, sino que su ser arte no había realmente emergido en la conciencia general y que, por lo tanto, no desempeñaban el papel de "obras de arte" tal como las obras de arte lo "vinieron a desempeñar cuando el concepto de arte al fin emergió y algo así como consideraciones estéticas comenzaron a gobernar nuestra relación con ellas.” Ni siquiera, agrega Danto, el concepto de "artista" entraba en la explicación de dichas imágenes. Es sólo a partir del Renacimiento cuando el concepto de artista se volvió central. Cfr. A.C. Danto, Después del fin del arte: el arte contemporáneo y el linde de la historia, pp. 25-26.

Diánoia, vol. LIV, no. 62 (mayo 2009). 
que artistas como Van Gogh o Gauguin produjeron a fines de 1880 ya no podía ser considerada en términos de imitación de la realidad, sino que requería una nueva teoría del arte. Los escritos de Clement Greenberg luego establecieron una narrativa histórica coherente que no sólo impuso nuevas reglas para la adecuación, sino que también introdujo una nueva concepción del progreso histórico. ${ }^{26}$ Danto presenta a Greenberg como el único que con el advenimiento de la pintura abstracta tuvo la habilidad para explicar lo que estaba sucediendo. El modelo de Greenberg es capaz de superar el reto de la ausencia de representación sobre el lienzo y el consiguiente colapso de toda teoría que tuviese los principios de la misma como fundamento. Greenberg pone el acento en dos elementos: la posibilidad de una crítica de la disciplina hecha desde la propia disciplina y el establecimiento del gusto como criterio. ¿Qué es lo que distingue a la pintura moderna? Debemos buscar la solución en la capacidad de autorreflexión que acompaña su desarrollo. La pintura moderna se piensa a sí misma o, mejor dicho, la pintura se hace transparente a sí misma. El único criterio que cabe seguir ahora no es el de adecuación a un criterio externo o una idea, sino a las exigencias del medio mismo. Greenberg entiende que el modernismo se ha percatado por fin de que la naturaleza del arte es filosófica. Pero, dentro de su concepción formalista, él entiende por esto último la purificación del género; es decir, el liberarse de cualquier elemento que sea ajeno a la pintura, liberando la creación de cualquier referencia ilusionista a un espacio tridimensional, y asegurando así la bidimensionalidad del lienzo.

La consideración que Greenberg hace del modernismo en función de la identificación progresiva y la exhibición de lo que es único e irreductible a los medios propios de cada una de las artes, es interpretada por Danto en términos hegelianos como la historia del arte alcanzando la autoconciencia. Esto es lo que proporciona la segunda gran narrativa del desarrollo histórico. El progreso en arte ya no es construido en términos de la conquista de la apariencia visual, sino en términos de una siempre mayor "adecuación filosófica". El modernismo es un intento por fundar cada una de las artes sobre un principio constante al descubrir su propia "esencia filosófica". ${ }^{27}$

\footnotetext{
${ }^{26}$ Para un desarrollo de la crítica y el análisis de Danto sobre Greenberg, véase el capítulo 4, supra. Clement Greenberg es una figura muy importante en el contexto norteamericano, personaje mítico de la crítica formalista y del reconocimiento del expresionismo abstracto. Danto le dedica el nudo de su texto.

${ }^{27}$ Cfr. A.C. Danto, Después del fin del arte, p. 68.
} 
Entonces - según Danto y en oposición al pronóstico de Greenberglos acontecimientos que siguieron al expresionismo abstracto demostraron que no era el medio, sino la naturaleza filosófica de la obra entendida como autoafirmación del mensaje, es decir, del hecho mismo de presentarse como obra, lo que constituía realmente la meta del arte. $\mathrm{El}$ arte pop desvela el punto final de ese proceso de adquisición de la conciencia de sí mismo que parece caracterizar el arte occidental desde sus orígenes hasta Warhol, pero con ello además se evidencia el hecho de que ese logro tiene un carácter histórico. Esto tiene una profunda importancia filosófica: estas narrativas ya no son aplicables a nuestras circunstancias históricas presentes y vivimos en la era de un pluralismo artístico en la cual nada está fuera de los límites.

El estadio final es el del "fin del arte". Surge con el advenimiento de un tipo de arte que exhibe que la identidad como obra de arte no puede ser deducida desde las propiedades sensibles del objeto en sí mismo. Situados ante objetos indiscernibles - recordemos las Brillo Box de Warhol-, las características visuales no pueden ser el criterio determinante. Más aún, en lo que a apariencias se refiere, cualquier cosa puede llegar a ser, ahora, una obra de arte. "No hay imperativos a priori sobre el aspecto de las obras de arte, sino que pueden parecer cualquier cosa." 28

\section{La tesis del fin del arte}

Desde que se ha escrito sobre el arte en relación a su historia, se ha dicho que esta historia alcanzaría un fin. En el primer tratamiento propiamente histórico del arte, la Historia natural de Plinio el Viejo, encontramos la afirmación de que el arte de bronce cesaría después de la Olimpíada. Giorgio Vasari describe en la edición de 1550 de sus Historias el trabajo de Miguel Ángel, que corporeiza el "fin y la perfección del arte". Nicolas Poussin se lamentó de que Caravaggio adviniera al mundo para destruir la pintura; Paul Delaroche anunció, al ver un daguerrotipo en 1839, que "a partir de hoy la pintura está muerta". Kazimir Malevich proclamó que en el suprematismo "no puede haber pregunta alguna sobre la pintura [...]; la pintura fue hecha hace mucho tiempo, y el artista en sí mismo es un prejuicio del pasado". Y finalmente, Walter Benjamin reclamó la famosa distinción entre obras de arte que poseen un aura, porque son únicas, y aquellas que se prestan a la reproducción mecánica, y por lo tanto, que tienen un lugar más

${ }^{28}$ Ibid., p. 37.

Diánoia, vol. LIV, no. 62 (mayo 2009). 
integrado en la experiencia colectiva. Douglas Crimp centró esta idea en el arte contemporáneo - definiéndola con relación a la existencia del museo- para proclamar, por su parte, "la condición terminal de la pintura". ${ }^{29}$

Pero al considerar estas aserciones individuales de que el arte en cierto modo ha terminado (Plinio), que ya no es más posible ni necesario (Poussin, Delaroche), o que es en su existencia continuada políticamente ilegítimo (Malevich, Crimp), vemos que lo que diferencia a Arthur Danto de estas interpretaciones es que él entiende que el arte tiene un fin porque su desarrollo histórico ha alcanzado una especie de final interno; un final derivado no de fuerzas externas aplicadas o contenidas, sino de la naturaleza del arte en sí misma. Su tesis sobre el fin del arte se sigue de su punto de vista sobre los desarrollos históricos del arte mismo, y cómo esos desarrollos han sido interpretados a partir de una necesidad interna o inmanente.

En una reciente formulación de su postura, Danto describe el desarrollo histórico del arte en Occidente caracterizado por dos episodios diferenciados, que denomina el "episodio Vasari" y el "episodio Greenberg". Sostiene, además, que ambos son progresivos. En primer lugar, Vasari, que construye el arte como representacional, concibe el desarrollo como la búsqueda por mejorar cada vez más "la conquista de las apariencias visuales". Esta narrativa alcanza un final cuando la imagen en movimiento probó ser más eficaz para retratar la realidad de lo que podía hacerlo la pintura misma. El modernismo se originó luego, con la irrupción de la pregunta sobre el lugar de la pintura; de este modo se originó el camino de la búsqueda de su propia identidad. Greenberg fue quien definió, precisamente, la nueva narrativa en términos de "un ascenso a las condiciones identificatorias del arte", y lo encontró en las condiciones materiales del medio. Pero ante la mirada de Danto, la narrativa de Greenberg llega a su fin con el arte pop: cuando el arte mismo reconoce que la obra de arte no tiene que ser de ninguna manera especial o determinada. ${ }^{30}$ Por lo tanto, el primer período de desarrollo, que se extiende desde Giotto de Bondone hasta los impresionistas, alcanza su fin cuando la misma teoría del arte así lo estableció; esto es, cuando ya no pudo sostener que el arte era esencialmente mimético. El modernismo se inició después de finalizado este desarrollo naturalista,

${ }^{29}$ Cfr. Encyclopedia of Aesthetics.

${ }^{30}$ Cfr. A.C. Danto, Después del fin del arte, p. 139. Quisiera mencionar aquí que Danto considera a Vasari como "el fundador de la historia del arte, al menos en el sentido en que él vió el arte como una narrativa de desarrollo progresivo" (ibid., p. 123). 
a través de los artistas y teóricos que miraron las formas del arte desde otras tradiciones no fundadas en el realismo óptico, tal como la exploración que hicieron los postimpresionistas de la pintura china y japonesa. Lo que caracteriza el desarrollo del arte desde ese momento hasta poco antes del trabajo de Andy Warhol es, para Danto, el progresivo intento de ofrecer, en lugar del ya nulo mandato hacia el naturalismo, una nueva teoría artística. La narrativa que advino luego, aquella en la que se incluye a Clement Greenberg, que va desde el impresionismo hasta la abstracción pospictórica, establece que el arte fue progresivamente realizando su "pureza" a través del derrumbe de todo aquello que no fuera específico para su medio. La teoría de Greenberg es importante para Danto, no por alguna verdad específica que pudiera contener, sino porque ejemplifica y describe la clase de práctica de autodefinición que orientó a las artes visuales durante el modernismo. Hay un desarrollo en este periodo del arte reflexivo y de autodefinición, pero el fin de ese desarrollo no es el descubrimiento de una respuesta a la pregunta por la esencia del arte, sino que el fin de dicho desarrollo se ubica en el momento en el cual son alcanzados los límites de la posibilidad de las obras de arte para ocuparse de tal autodefinición. Aunque el límite de la teorización sobre sí mismo del arte está marcado por muy diversas obras dentro del mundo del arte, se encuentra expresado para Danto en las Brillo Box de Warhol más vívidamente. Allí la pregunta "¿qué es el arte?" se ubica en su forma adecuada, al cuestionar qué es lo que distingue una obra de arte de un objeto ordinario cuando ambos son, desde lo sensible, indiscernibles.

Ya no es posible un desarrollo de la historia del arte porque, ahora que la pregunta acerca del arte es puesta en su forma adecuada, el arte no parece ser la clase de práctica propia que sirva para dar una respuesta. En la teoría de Danto, el arte deviene filosofía.

Para Danto, así como la filosofía se ha convertido en su propio tema, es decir, se ha vuelto reflexivamente sobre sí misma, el arte también se convierte cada vez más en su propio tema. En ello ve una analogía con el Absoluto de Hegel, que finalmente logra la congruencia consigo mismo al volverse autocontemplativo. Danto otorga un valor revolucionario al hecho de que las fronteras entre la realidad y el arte se hayan convertido, en efecto, en fronteras internas al arte mismo. ${ }^{31}$ Una consecuencia interesante que Danto sigue de esto es que:

La distinción entre la filosofía del arte y el arte mismo ya no es sostenible $y$, por un curioso y asombroso acto de magia, nos hemos convertido en

${ }^{31}$ Cfr. A.C. Danto, “Obras de arte y cosas reales", pp. 39-40. 
personas que aportamos a un ámbito al que siempre habíamos creído que debíamos analizar desde fuera. ${ }^{32}$

Esta consideración se sigue de la idea de que la relación entre arte y realidad ha sido tradicionalmente la provincia de la filosofía, pues para Danto, esta última se ocupa analíticamente de las relaciones entre el mundo y sus representaciones, del espacio que existe entre la representación y la vida. Al traer dentro de sí aquello que tradicionalmente había sido considerado como algo lógicamente separado de él, el arte se transforma asimismo en filosofía.

La propia reflexión de Danto - este punto él lo ha explicado muchas veces- es que el fin de la historia del arte significa, simplemente, que dado que el arte ya no responde a una necesidad interna de desarrollo, ahora todas las cosas son posibles. El leit-motiv de la argumentación de Danto —que "la historia del arte ha llegado a su fin"- ha traído aparejados muchos malentendidos. Se la ha interpretado como una tesis sociológica, o una afirmación sobre los méritos del arte contemporáneo. Pero Danto no asevera ni sugiere en estas tesis que el mercado de arte contemporáneo esté sobreextendido, tampoco lo niega. Además, su filosofía no pretende ser una visión general sobre la calidad del arte contemporáneo. Su análisis trasciende estas preocupaciones particulares. Como Danto ha especificado con esmero, su teoría estética está naturalmente asociada con su perspectiva general, familiar a la filosofía analítica: una perspectiva que simplemente pretende mostrar cómo es el mundo. Danto ha observado y aclarado reiteradas veces que su teoría estética general no debe confundirse con los juicios particulares que realiza como crítico de arte. En el terreno del arte a veces se habla de un "final" cuando no emergen verdaderamente nuevas figuras significativas. Pero la tesis esencial de Danto no es de esta clase, sino que realiza una afirmación metafísica, no un juicio sobre la calidad del arte reciente. Una teoría estética debe ser general y compatible con todas las clases de arte; la crítica, por el contrario, se ocupa de casos individuales. La noción de Danto del fin de la historia del arte es compatible con la aparición de nuevos y excelentes artistas; por cierto, como crítico, Danto ha respondido positivamente a muchas de tales figuras. ${ }^{33}$

Evidentemente, seguirán produciéndose obras de arte, pero los artífices, viviendo en lo que yo he dado en llamar "el periodo posthistórico del

${ }^{32}$ Ibid.

${ }^{33}$ Cfr. D. Carrier, "Danto and His Critics: Art History, Historiography and After the End of Art", pp. 1-16. 
arte", crearán obras carentes de la importancia o el significado histórico que tradicionalmente se les atribuye. El estadio histórico del arte finaliza cuando se sabe lo que es el arte y lo que significa. ${ }^{34}$

Claramente, tal fin de la historia del arte no es un hecho que tenga mucho efecto en la vida cotidiana del mundo del arte.

\section{El "renacimiento hegeliano"}

Considerar la historia del arte moderno en términos de una búsqueda filosófica posee una sorprendente semejanza con el pensamiento hegeliano. La lectura que hace Danto de Hegel, como lo ha reconocido recientemente, responde fundamentalmente a la interpretación de Alexandre Kojève, quien ilustra en sus principales textos la tesis acerca del "realismo" filosófico de Hegel en oposición al "idealismo" dentro del cual se acostumbra clasificarlo. Al hacer de la propia filosofía uno de los temas centrales, el pensador alemán, bajo la mirada de Kojève, la define como la única explicación de la Historia - devenir del Espíritu que es, a su vez, devenir histórico del hombre-, acotando que una vez explicada totalmente, o revelada la historia, la filosofía deja de tener sentido, se hace innecesaria. El hombre se ha explicado a sí mismo y, por lo tanto, ha concluido su ciclo histórico. ${ }^{35} \mathrm{El}$ análisis que Danto hace del arte en su desarrollo histórico es completamente análogo. Una vez que ha sido revelada la esencia del arte, una vez que el arte se ha comprendido a sí mismo, su historia ha concluido.

La diferencia entre Danto y Hegel, sin embargo, es evidente al analizar los distintos modos en que ellos interpretan la afirmación de que el arte es "pasado" en su más alta vocación. En realidad, ésta es la concepción que se expresa cuando se habla de "muerte del arte" -frase que, por cierto, no aparece en su obra- a partir de la visión de Hegel. ${ }^{36}$ Hegel sostuvo que el arte en su más alta vocación es cosa del pasado, en tanto es desplazado por la religión y por la filosofía en el despliegue del espíritu. Para Danto, esta vocación consiste principalmente en desarrollarse hacia su propio autoconocimiento, hacia su propia auto-

${ }^{34}$ A.C. Danto, "El final del arte", p. 22.

${ }^{35}$ Cfr. J. Fernández Vega, "Arthur Danto: una libertad sin esperanza". Cfr. A. Kojève, La concepción de la antropología y del ateísmo en Hegel, y La dialéctica de lo real y la idea de la muerte en Hegel.

${ }^{36}$ Los textos que corroboran la tesis de la muerte del arte pertenecen en su mayoría a la introducción de las Lecciones de estética y al epígrafe de la primera parte. 
conciencia. Para Hegel, "la más alta vocación" tiene que ver con el arte en conexión con la vida política, religiosa y social de un modo que ya no es posible en los tiempos modernos. La historia ya no condiciona políticamente al artista.

Como correctamente sostiene Danto, Hegel fue el primero en advertir que había fronteras históricas irrebasables para las producciones. Una obra habla necesariamente de una forma peculiar (es decir histórica) de vida, las creaciones no son a priori puesto que se desarrollan en un momento peculiar, objetivo. ${ }^{37}$

Danto afirma que ahora es más tolerante con las historias especulativas como la de Hegel que cuando publicó Analytical Philosophy of History. Esta afirmación es importante, aun cuando, en rigor, After the End of Art adopta un hegelianismo muy limitado. ${ }^{38}$ Lo que en Analytical Philosophy of History cuestionaba a las historias especulativas era su afirmación de ser capaces de escribir narrativas completas del pasado, del presente y del futuro, una afirmación inconsistente, como hemos visto, con la naturaleza básica de lo narrativo en sí y sus sentencias características. Sin embargo admite ahora: "se ha vuelto más y más plausible para mí que existen estructuras históricas objetivas. [...] una señal de que el arte terminó es la de que ya no existe una estructura objetiva para definir un estilo o, si se prefiere, que debe haber una estructura histórica objetiva en la cual todo es posible". ${ }^{39}$

Todo es posible en esta era posthistórica; un artista "puede ser un expresionista abstracto, o un artista pop, o un realista, o cualquier cosa". Y ésta es aproximadamente la condición del fin de la historia descrita por Marx y Engels en La ideología alemana. Los artistas son ahora libres, como el hombre posrevolucionario de Marx, para habitar el libre espacio de la creación. Lo que ahora define al arte es su condición de haberse realizado a sí mismo. Ésta es la concepción de Danto del posmodernismo, una concepción utópica y celebratoria.

Por tanto, para volver a uno de sus ejemplos conocidos, nadie que sea testigo de la ascensión de Petrarca al Monte Ventoux pudo haber dicho: "Petrarca está inaugurando el Renacimiento", porque tal juicio sólo puede ser hecho en una fecha posterior. No sabemos lo que los historiadores

${ }^{37}$ J. Fernández Vega “¿Buenas noticias sobre la 'muerte del arte’?: arte, historia y política entre el comunitarismo hegeliano y el individualismo de Danto".

${ }^{38}$ Cfr. D. Carrier, op. cit.

${ }^{39}$ A.C. Danto, Después del fin del arte, p. 64. Para el tema del "estilo" en relación con las estructuras históricas objetivas. Cfr. ibid., pp. 66-76. 
del futuro van a decir sobre nosotros. Ésta era una de las características del narrativismo: narramos desde la perspectiva de la conclusión. En la Fenomenología, Hegel parece estar escribiendo una historia completa del presente, y puede hacerlo porque cree que la historia ha terminado. Análogamente, ahora que la historia del arte ha terminado, Danto piensa que podemos escribir una historia del arte completa: porque sabemos cómo ha terminado. ${ }^{40}$ Las afirmaciones acerca del futuro que Danto realiza están vinculadas a sus expresiones acerca del estado final del arte y de la conclusión de un proceso histórico determinado. El fin y cumplimiento de la historia del arte es la comprensión filosófica de lo que el arte es. Verdaderamente, esto está reflejado en no haber en el arte contemporáneo un mandato en el estilo - o estilos- que establezca un desarrollo estructurado narrativamente. La afirmación de que el arte ha terminado es una afirmación acerca del futuro: no se trata de la presunción de que ya no habrá más arte, sino que el arte ahora será arte después del fin del arte o, como él lo denomina, arte posthistórico. ${ }^{41}$

Su visión sobre la naturaleza del arte aparece de un modo totalmente diferente cuando se coloca en el nuevo contexto. Al mover su argumento desde el marco dado por la filosofía analítica a la perspectiva provista por la historiografía de Hegel, Danto inevitablemente cambia su visión. ${ }^{42}$

Si su Analytical Philosophy of History menciona a Hegel sólo de pasada es porque la meta de Danto era más bien proponer una alternativa al análisis de Hempel, y una discusión en profundidad sobre la historiografía de Hegel hubiera sido irrelevante. Más aún, cuando Danto critica el modelo de las "filosofías sustantivas de la historia" sugiere que la filosofía especulativa de la historia ejemplificada por la Fenomenología del espíritu es cognoscitivamente ilegítima. ${ }^{43}$

Arthur C. Danto da un giro en el que parece ligar su noción de narrativa con la comprensión hegeliana de la historia como autodespliegue, como autoexplicación. Danto se inspira en la visión de Hegel al ofrecer una teoría que pone el acento en lo autorreferencial, en el carácter de "mirada interna" o de introspección del arte reciente: el propósito del progreso histórico del arte ha sido la revelación de su propia esencia. Esta forma de interpretar la historia del arte remite, según Danto, a un modelo global de la historia del arte narrativamente ejemplificado "por

${ }^{40}$ Cfr. D. Carrier, op. cit.

${ }^{41}$ Ibid., p. 64.

${ }^{42}$ Ibid.

${ }^{43}$ Ibid. 
la Bildungsroman, la novela de aprendizaje que culmina en el autorreconocimiento del arte". ${ }^{44}$ Danto traslada esta noción a la Fenomenología del espíritu de Hegel, la cual adoptaría esta forma de desarrollo, siendo el "héroe" el "espíritu del mundo" (Geist) y cuyos estadios evolutivos hacia el autoconocimiento y hacia la autorrealización a través del autoconocimiento se trazan dialécticamente. El arte, entonces, es uno de esos estadios, pero es un estadio que debe ser superado. Según el esquema de Hegel, como ya hemos mencionado, la culminación de la búsqueda y el destino del Geist es la filosofía.

La interesante idea que Danto toma de Hegel es la función cognitiva del arte, esto es, su aspiración al autoconocimiento. ${ }^{45} \mathrm{El}$ arte para Hegel, como también para Danto, apela a nuestro juicio, puesto que sometemos a nuestra consideración su contenido. Hegel ha escrito:

El arte como ciencia es más necesario en nuestro tiempo que cuando el arte como tal producía ya una satisfacción plena. El arte nos invita a la contemplación reflexiva, pero no con el fin de producir nuevamente arte, sino para conocer científicamente lo que es el arte. ${ }^{46}$

Sin embargo, sale a la superficie un cambio crucial en el uso que hace Danto de la noción de "autoconocimiento": ahora se habla del arte como el sujeto de autoconocimiento, siendo su meta histórica alcanzar el conocimiento de lo que es en sí mismo (o lo que la pintura, la escultura y lo demás son en sí). Este proceso puede, por lo tanto, ser puesto en paralelo con la narrativa de una persona que alcanza su propia identidad a través del autoconocimiento. ${ }^{47}$ De aquí la analogía con la Bildungsroman.

Danto enlaza estas reflexiones con el valor dado a la teoría, al establecer que la importancia histórica del arte reside en hacer que la filosofía del arte sea posible e importante. Danto nos invita a mirar el arte moderno para encontrarnos con un arte que depende cada vez más de una teoría para ser considerado como tal; la teoría ya no es ajena a la comprensión de las obras. Además, Danto señala que estas

${ }^{44}$ Cfr. A.C. Danto, "El final del arte". La Bildungsroman (al. "novela de formación") es aproximadamente sinonímico de novela de "crecimiento" o "educación". Es un término ampliamente usado por los críticos alemanes; se refiere a una novela que es el relato del desarrollo juvenil de un héroe o heroína. Describe los procesos por los cuales se alcanza la madurez, el autoconocimiento, a través de las idas y vueltas de la vida.

${ }^{45}$ Cfr. B. Hilmer, "Being Hegelian after Danto".

${ }^{46}$ G.W.F. Hegel, Estética I, p. 17.

${ }^{47}$ Cfr. A.C. Danto, Después del fin del arte, p. 68.

Diánoia, vol. LIV, no. 62 (mayo 2009). 
producciones poseen otra característica fundamental, esto es, que "los objetos tienden a desaparecer mientras su teoría tiende al infinito". Por ello, llega a afirmar:

Al final, virtualmente, lo único que hay es teoría: el arte se ha volatilizado en un resplandor de mera auto-reflexión, convertido en el objeto de su propia consciencia teórica. En el caso de que algo como esto fuera remotamente verosímil, podríamos suponer que el arte habría llegado a su fin. ${ }^{48}$

La interpretación de las tesis de Hegel es difícil y discutida y no pretendemos estudiarla aquí, dado que merece un desarrollo que excede las pretensiones de este trabajo. Pero es preciso señalar que cualquiera sea la interpretación apropiada, es claro que la teoría de Hegel del arte presupone su más general filosofía de la historia.

Sin embargo, la interpretación que Danto hace de Hegel es generalmente aceptada en relación con el papel que Hegel representó como precursor del encuadre histórico de la estética. Pero, claramente, Danto no coincide con el historicismo de Hegel cuando éste entra en conflicto con la autonomía del arte. Danto no establece en ningún momento una jerarquía ni tampoco sugiere el lugar que ocuparía la estética en una totalidad, orden que en Hegel tiene fundamental importancia. ${ }^{49}$

Por supuesto, Danto está al tanto de las conexiones y paralelos que la historia del arte tiene con los otros fenómenos filosóficos e históricos, pero esto no impone nada sobre la función que el arte pueda tener en el proceso histórico o social. ${ }^{50}$ Danto ha expresado reiteradamente su deuda con la estética de Hegel, y una vez señalado que abandona el resto del sistema hegeliano, es posible comprender los límites de la apropiación de su pensamiento, pero también su originalidad. Danto mismo reconoce que es difícil saber hasta dónde es posible separar la visión histórica de Hegel del cuerpo general de su pensamiento; y, además, admite que aunque ha hablado de su "renacimiento hegeliano", no es claro cuánto más puede aceptar de su sistema. ${ }^{51}$

${ }^{48}$ Ibid.

49 J. Fernández Vega sostiene que, en Danto, "la situación del arte contemporáneo -y de la disciplina que lo estudia - respecto de un conglomerado espiritual más amplio queda [...] indeterminado” (J. Fernández Vega, “¿Buenas noticias sobre la 'muerte del arte'?").

${ }^{50} \mathrm{Cfr}$. B. Hilmer, op. cit.

${ }^{51}$ A.C. Danto, Beyond the Brillo Box: The Visual Arts in Post-Historical Perspective, p. 9.

Diánoia, vol. LIV, no. 62 (mayo 2009). 
La cuestión crítica obvia es que el acercamiento de Danto a la historiografía en After the End of Art es sólo en parte hegeliana. A diferencia de Hegel, Danto habla sólo de la historia del arte, no de la historia en general; y esto significa que el arte puede alcanzar la autoconciencia sin que la cultura más amplia también encuentre ese punto final.

Danto ha redimido algunas de las reflexiones más interesantes de Hegel al incorporarlas dentro de su propia teoría. No obstante, expresa con claridad que se trata de cuestiones vinculadas a un campo limitado. ${ }^{52}$ Danto se apropia primordialmente de la filosofía de la historia del arte y de la tesis del fin del arte de Hegel, pero es muy cauteloso en relación con el sistema hegeliano como una totalidad y con su fundamento metafísico. ${ }^{53}$

\section{Conclusiones}

Nos hemos acercado primero a las consideraciones de Danto sobre filosofía de la historia, dado que presenta elementos clave para sus nuevas aportaciones en materia estética. Las consideraciones sobre la historia alejan a Danto de la filosofía positivista hacia una reflexión donde la noción de "narración" es central. Esta narración tiene un carácter autoexplicativo, es decir, explica los acontecimientos sin necesidad de referirse a elementos externos a la narración misma. La estructura intrínseca de la narración es la categoría sobre la que descansa la disciplina historiográfica. Danto, realizando un giro sorprendente respecto de sus primeras reflexiones teóricas sobre el arte, introduce elementos de su concepción de la historia para proponer una filosofía de la historia del arte a partir del análisis de las narrativas del arte occidental. La historiografía penetra ahora en la problemática estética y la problemática se

${ }^{52}$ Lo que puede volverse un punto interesante para procurar un diálogo entre Danto y Hegel es el proyecto al que ambos atienden, esto es, enlazar esencialismo e historia. En la teoría de Danto, esta conexión ha estado entre sus puntos más discutidos. Nöel Carroll ha impugnado la circularidad en la defensa de Danto de su teoría del arte esencialista, al introducir una teoría de la historia del arte que presupone su mismo concepto de arte. La problemática del esencialismo y del historicismo en Danto representa uno de los puntos clave en su filosofía, pero su exposición aquí excede los límites del trabajo. Cfr. V. Parselis, “¿Puede el arte ser definido? Controversias sobre la definición del arte en la estética contemporánea y la propuesta de Arthur C. Danto"; B. Hilmer, op. cit.; N. Carroll, "Essence, Expression and History: Arthur Danto's Philosophy of Art", p. 98.

${ }^{53}$ Ernst Gombrich ya ha señalado los problemas que surgen del "hegelianism without Metaphysics", quedando el "hegelianismo" reducido a la idea de una historia cultural progresiva. Cfr. E. Gombrich, Ideal and Idols. 
extiende hacia la comprensión del nexo entre la definición del arte y su posibilidad histórica.

En la temprana obra de filosofía de la historia, Danto desestimaba, por una parte, al positivismo, pero también a las llamadas "filosofías sustantivas de la historia", fundamentalmente por proyectarse hacia el futuro, como si los filósofos fueran "profetas" y tuvieran un "privilegio cognitivo" acerca del devenir futuro del arte. Ahora, al introducir una perspectiva de fuerte inspiración hegeliana, Danto afirma que la historia del arte ha llegado a su fin. Su afirmación sobre el fin del arte puede ser comprendida en cierto sentido como una "afirmación acerca del futuro": el anuncio del arte después del fin del arte o arte posthistórico. ¿Cómo admitir esta nueva actitud frente a la historia? ¿Cómo legitimar este salto en las aseveraciones acerca del destino del arte? Parecería que la respuesta está en la manera en que se combinan por un lado las lecturas del historicismo de Hegel con su temprana noción de narrativa. "Se ha vuelto más plausible para mí que existen estructuras históricas objetivas", dice Danto. ${ }^{54}$ Vivimos y producimos dentro de un horizonte histórico cerrado; pero el presente se ilumina como la revelación de una urdimbre de sentido. Narramos la historia desde el fin del relato, comprendiendo ahora la historia como el despliegue de una necesidad inmanente, por tratarse de estructuras objetivas.

Las influencias de Wölfflin, y de Hegel mismo, conducen a Danto hacia la consideración de la historia del arte como un despliegue, una autoexplicación, como la autocomprensión y la búsqueda de su propia esencia. Para Danto, el arte moderno ha internalizado la verdad de que el arte tiene una historia y que la búsqueda de su esencia determina su lógica. El arte moderno inauguró la búsqueda histórica de autodefinición. ${ }^{55} \mathrm{El}$ fin del arte adviene, por lo tanto, cuando la narrativa dominante que generó un desarrollo histórico progresivo alcanzó su propio fin. Y esto surge precisamente con el advenimiento de un arte que alcanza el nivel de autoconciencia sobre su propia esencia. Es el fin del relato y podemos denominarlo, junto con Danto, más bien como "una profecía del presente": el momento final en la narrativa maestra. El futuro sigue siendo una incógnita. No sabemos cómo nos verán

${ }^{54}$ A.C. Danto, Después del fin del arte, p. 63.

${ }^{55}$ Para este tema es interesante ver la crítica que realiza Daniel Herwitz a Danto sobre la reducción de los movimientos de vanguardia a la tarea de autodefinición, dejando de lado su visión utópica y sociopolítica. D. Herwitz, "The Beginning of the End: Danto on Posmodernism", pp. 143-147; cfr. la respuesta de Danto en M. Rollins (comp.), Danto and His Critics, p. 212. Cfr. también D. Herwitz, Making Theory. Constructing Art: On the Authority of the Avant-Garde. 
los historiadores. Somos sujetos históricamente situados que narramos la historia pasada a partir de la condición del arte presente. El arte, como el lenguaje, habla al mundo, y siempre desde un punto de vista determinado. Las obras de hoy son completamente abiertas, aunque dentro de un marco histórico preciso.

Danto, fiel al espíritu de nuestro tiempo, crea un fascinante y complejo collage filosófico que enlaza en un entramado coherente tradiciones sobre el pasado y el presente (y el futuro), aparentemente tan diversas.

\section{BIBLIOGRAFÍA}

Belting, H., Likeness and Presence: A History of Image before the Era of Art, The Chicago University Press, Chicago, 1994.

Birulés, F., "Introducción”, en Danto, Historia y narración, pp. 9-27.

Carrier, D., "Danto and His Critics: Art History, Historiography and After the End of Art", History and Theory, vol. 37, no. 4, diciembre de 1998, pp.1-16. Carroll, N., "Essence, Expression and History: Arthur Danto's Philosophy of Art", en Rollins (comp.) Danto and His Critics, pp. 79-106.

- (comp.), Theories of Art Today, The University of Wisconsin Press, Madison, 2000.

Collingwood, R.G., Idea de la historia, trad. Edmundo O'Gorman y Jorge Hernández Campos, Fondo de Cultura Económica, México, 1993.

Danto, A.C., "Art, Essence, History, and Beauty: A Reply to Carrier, a Response to Higgins", Journal of Aesthetics and Art Criticism, vol. 54, no. 3, 1996, pp. 284-287.

— Beyond the Brillo Box: The Visual Arts in Post-Historical Perspective, FarrarStraus-Giroux, Nueva York, 1992.

—_, Después del fin del arte: el arte contemporáneo y el linde de la historia, trad. Elena Neerman, ed. revisada por Radamés Molina, Paidós, Barcelona, 2000.

—_, El abuso de la belleza, trad. Carles Roche, Paidós, Barcelona, 2005.

—_, "El final del arte", El paseante, nos. 22-23, 1995, pp. 1-25.

— Historia y narración, trad. Eduardo Bustos, Paidós, Barcelona, 1989.

—, "Mere Chronicle and History Proper", Journal of Philosophy, vol. 50, no. 6, 1953, pp. 173-182.

—-, "Narrative and Style", The Journal for Aesthetics and Art Criticism, vol. 49, no. 3, verano de 1991, pp. 201-209.

__, "Obras de arte y cosas reales", Ensayos. Historia y teoría del arte, año 1998-1999, no. 5, pp. 41-68.

__ " "On Historical Questioning", Journal of Philosophy, vol. 51, no. 3, 1954, pp. 89-99.

- , Philosophizing Art: Selected Essays, University of California Press, Berkeley, 1999. 
Danto, A.C., The Madonna of the Future: Essays in a Pluralistic Art World, FarrarStraus-Giroux, Nueva York, 2000.

- The Philosophical Disenfranchisement of Art, Prentice Hall, Nueva York, 1986.

- The State of the Art, Prentice Hall, Nueva York, 1986.

- The Transfiguration of the Commonplace, Harvard University Press, Cambridge, 1981. [Versión en castellano: La transfiguración del lugar común: una filosofía del arte, trad. Ángel y Aurora Molla Román, Paidós, Barcelona, 2002.]

— , "Works in Progress: Art and the Historical Modalities", en Jean-Paul Riopelle (comp.), L'Hommage à Rosa Luxemburg, 1992.

Dray, W., Laws and Explanation in History, Oxford University Press, Londres, 1957.

Encyclopedia of Aesthetics, Oxford University Press, Nueva York, 1998.

Fernández Vega, J., "Arthur Danto: una libertad sin esperanza", Clarín, Buenos Aires, 8 de abril de 2001.

— entre el comunitarismo hegeliano y el individualismo de Danto", Signos Filosóficos, no. 4, julio-diciembre de 2001, pp. 119-134.

Gaiger, J., "Danto's Philosophy of Art History", Art History, vol. 22, no. 3, septiembre de 1999, pp. 451-456.

Gallie, W., Philosophy and Historical Understanding, Schocken Books, Nueva York, 1964.

Gombrich, E., Ideal and Idols, Oxford University Press, Oxford, 1979.

Greenberg, C., Art and Culture: Critical Essays, Beacon Press, Boston, 1961.

Gyorgy, P., "Between and After Essentialism and Institutionalism", Journal of Aesthetics and Art Criticism, vol. 57, no. 4, 1999, pp. 421-437.

Habermas, J., La lógica de las ciencias sociales, trad. Manuel Jiménez Redondo, Tecnos, Madrid, 1988.

Hegel, G.W.F., Estética, trad., estudio y pról. Alfredo Llanos, Siglo XX, Buenos Aires, 1985.

— - Introducción a la estética, trad. Ricardo Mazo, Península, Barcelona, 1973.

Hempel, C., La explicación científica, trad. M. Frassineti de Gallo, Néstor Míguez e Irma Ruiz Aused, Paidós, Buenos Aires, 1979.

-, "The Function of General Laws in History", Journal of Philosophy, vol. 39, 1942, pp. 35-48.

Herwitz, D., Making Theory. Constructing Art: On the Authority of the AvantGarde, The University of Chicago Press, Chicago, 1993.

— , "The Beginning of the End: Danto on Posmodernism", en Rollins (comp.) Danto and His Critics , pp. 142-158.

Hilmer, B., "Being Hegelian after Danto", History and Theory, vol. 37, no. 4, 1998, pp. 71-87.

Jiménez, J., “¿Muerte o futuro del arte?”, Taula: Quaderns de Pensament, nos. 33-34, 2000, pp. 71-77. 
Kojève, A., La concepción de la antropología y del ateísmo en Hegel, La Pléyade, Buenos Aires, 1972.

_- La dialéctica de lo real y la idea de la muerte en Hegel, La Pléyade, Buenos Aires, 1972.

Labrada, M.A., Belleza y racionalidad, Eunsa, Pamplona, 1990.

Margolis, J., "A Closer Look at Danto's Account of Art and Perception: Response to Arthur Danto", The British Journal of Aesthetics, vol. 40, no. 3, julio de 2000, p. 326.

Martínez, C., "La sombra de una duda: Arthur Danto y la narrativa del fin del arte", Lateral, no. 60, diciembre de 1999, pp. 37-39.

Mink, L.O., Historical Understanding, Cornell University Press, Ithaca, 1987.

Parselis, V., "¿Puede el arte ser definido? Controversias sobre la definición del arte en la estética contemporánea y la propuesta de Arthur C. Danto", Sapientia, vol. 63, fasc. 223, 2008, pp. 143-158.

Ricœur, P., Tiempo y narración, trad. Agustín Neira, Cristiandad, Madrid, 1987.

Riegl, A., Problemas de estilo, trad. Federico Miguel Saller, G. Gili, Madrid, 1980.

Rollins, M. (comp.), Danto and His Critics, Blackwell, Oxford, 1993.

- "The Invisible Content of Visual Art", Journal of Aesthetics and Art Criticism, vol. 59, no. 1, enero de 2001, pp. 19-28.

Vasari, G., Las vidas de los más excelentes arquitectos, pintores, escultores italianos desde Cimabue hasta nuestros tiempos, trad. Helena Aguila et al., Cátedra, Madrid, 2002.

Vilar, G., El desorden estético, Idea Books, Barcelona, 2000.

White, M., Historical Knowledge, Greenwood Press, Westport, 1965.

White, H., Metahistory: The Historical Imagination in Nineteenth-Century Europe, The Johns Hopkins University Press, Baltimore, 1973. [Versión en castellano: Metahistoria. La imaginación histórica en la Europa del siglo XIX, trad. Stella Mastrangelo, Fondo de Cultura Económica, México, 1992.]

Winch, P., The Idea of a Social Science, Routledge and Kegan Paul, Londres, 1948. [Versión en castellano: Ciencia social y filosofía, Amorrortu, Buenos Aires, 1972.]

Wölfflin, H., Conceptos fundamentales de la historia del arte, trad. José Moreno Villa, Espasa-Calpe, Pozuelo de Alarcón, 1997.

Yturbe, C., "El conocimiento histórico", en Enciclopedia Iberoamericana de filosofía, ed. Reyes Mate, Trotta, Madrid, 1993, v. 5.

Recibido el 17 de diciembre de 2007; aceptado el 19 de noviembre de 2008. 